\title{
Koordinasi Proteksi Saluran Udara Tegangan Tinggi pada Gardu Induk Mliwang - Tuban Akibat Penambahan Penghantar Pltu Tanjung Awar-Awar
}

\author{
Henry Haskarya, Margo Pujiantara, dan Arif Musthofa \\ Jurusan Teknik Elektro, Fakultas Teknologi Industri, Institut Teknologi Sepuluh Nopember (ITS) \\ J1. Arief Rahman Hakim, Surabaya 60111 Indonesia \\ e-mail:margo@ee.its.ac.id, arif@ee.its.ac.id
}

\begin{abstract}
Abstrak-Dengan pertumbuhan penduduk, perumahan, dan industry, dan juga untuk meningkatkan kapasitas penyediaan energi litrik dimasa mendatang maka perlu ditambah adanya pembangkit baru untuk mengatasi kebutuhan listrik tersebut. Karena alasan tersebut maka di bangunlah PLTU Tanjung Awar-Awar sebagai unit pembangkit baru di PLN-APP Madiun. Pembangunan PLTU Tanjung Awar-Awar menyebabkan perubahan konfigurasi jaringan tenaga listrik, khususnya dalam jaringan transmisi tegangan tinggi. Konfigurasi Saluran Udara Tegangan Tinggi (SUTT) yang berubah akibat adanya PLTU ini salah satunya adalah SUTT Mliwang - Tuban. Umumnya setiap perubahan konfigurasi jaringan tentunya akan disertai dengan perubahan setting pengamannya. Untuk itu perlu di adakan resetting ulang koordinasi pengaman pada jaringan yang baru. Hasil dari resetting dan analisa di dapat bahwa setting pada zona 1 dan zona 2 hampir sama dengan setting existing PLN, namun di zona 3 berbeda, maka dari itu perlu di lakukan pengkajian ulang system proteksi transmisi yang ada.
\end{abstract}

Kata Kunci- koordinasi proteksi, rele jarak, rele arus lebih.

\section{PENDAHULUAN}

$\mathrm{P}$ ENULISAN pertumbuhan penduduk, perumahan, dan industry, dan juga untuk meningkatkan kapasitas penyediaan energi litrik dimasa mendatang maka perlu ditambah adanya pembangkit baru untuk mengatasi kebutuhan listrik tersebut. Karena alasan tersebut maka di bangunlah PLTU Tanjung awar-awar sebagai unit pembangkit baru di PLN-APP Madiun. Pembangunan PLTU Tanjung Awar-Awar menyebabkan perubahan konfigurasi jaringan tenaga listrik, khususnya dalam jaringan transmisi tegangan tinggi.

Konfigurasi Saluran Udara Tegangan Tinggi (SUTT) yang berubah akibat adanya PLTU ini salah satunya adalah SUTT Mliwang-Tuban. Umumnya setiap perubahan konfigurasi jaringan tentunya akan disertai dengan perubahan setting pengamannya. Untuk itu perlu di adakan re-setting ulang koordinasi pengaman pada jaringan yang baru.

Fungsi sistem proteksi adalah untuk memutus arus gangguan yang muncul dengan cepat dan selektif. Ketika arus gangguan muncul maka sistem proteksi harus dapat memutus arus gangguan tersebut dengan cepat sebelum terjadi kerusakan pada peralatan serta membatasi dampak gangguan agar tidak meluas ke seluruh sistem. Oleh sebab itu, sistem proteksi harus di-setting sedemikian rupa agar sistem proteksi tersebut dapat melakukan fungsinya dengan baik.

Penambahan pembangkit tersebut dapat menyebabkan setting proteksi yang ada tidak sesuai lagi dengan kondisi yang baru. Pada Tugas Akhir ini akan membahas mengenai koordinasi proteksi SUTT antara GI Mliwang-Tuban akibat adanya penambahan pembangkit Tanjung Awar-Awar. Analisa koordinasi proteksi SUTT antara GI Mliwang-Tuban yang meliputi breaking capacity, perhitungan resetting proteksi (relai jarak, relai arus lebih). Sehingga dengan adanya desain dan setting yang tepat maka diharapkan sistem proteksi menjadi efisien dan dapat bekerja dengan cepat dan selektif memutus arus gangguan.

Sistem proteksi tenaga listrik karena berbagai macam factor dapat mengalami kegagalan operasi sehingga diperlukan proteksi cadangan atau back-up protection yang akan bekerja jika proteksi utama gagal bekerja. Saluran udara tegangan tinggi menggunakan rele jarak sebagai proteksi utama dan dilengkapi proteksi cadangan local serta proteksi cadangan jauh. Sistem proteksi cadangan local menggunakan rele arus lebih (OCR), sedangkan proteksi cadangan jauh menggunakan zona dua rele jarak dari gardu induk yang lain. Sistem proteksi utama dan proteksi cadangan harus dikoordinasikan agar dapat bekerja secara selektif.

\section{TEORI PENUNJANG}

\section{A. Gangguan Hubung Singkat}

Dalam setiap sistem kelistrikan di industri tidak dapat lepas dari kemungkinan adanya gangguan, baik gangguan yang bersumber dari dalam sistem sendiri (internal) maupun dari luar (external). Gangguan yang sering terjadi pada suatu sistem kelistrikan industri adalah gangguan hubung singkat. gangguan ini disebabkan adanya saluran fasa yang terhubung dengan saluran fasa lainnya atau terhubung dengan ground. Gangguan ini dapat meyebabkan terjadinya arus yang sangat besar sehingga dapat merusak peralatan listrik yang ada di sekitar titik gangguan. Besarnya arus gangguan hubung singkat dapat ditentukan berdasarkan impedansi dari peralatan listrik pada 
sistem tersebut. Gangguan hubung singkat dapat terjadi tiga fasa, dua fasa, satu fasa ke tanah, dua fasa ke tanah, atau 3 fasa ke tanah.

\section{B. Rele Jarak}

Pada proteksi saluran udara tegangan tinggi, rele jarak digunakan sebagai pengaman utama sekaligus sebagai pengaman cadangan untuk saluran transmisi yang berdekatan. Hal ini didasarkan bahwa impedansi saluran transmisi berbanding lurus dengan jaraknya sehingga memungkinkan dilakukan pengukuran impedansi berdasarkan panjang salurannya. Prinsip dasar dari rele jarak atau distance relay adalah berdasarkan rasio perbandingan tegangan dan arus gangguan yang terukur pada lokasi rele terpasang (apparent impedance), untuk menentukan apakah gangguan yang terjadi berada di dalam atau di luar zona yang diproteksinya. Rele jarak hanya bekerja untuk gangguan yang terjadi antara lokasi rele dan batas jangkauan (reach setting) yang telah ditentukan. Rele jarak juga dapat bekerja untuk mendeteksi gangguan antar fasa (phase fault) maupun gangguan ke tanah (ground fault).. Berikut skema pada rele jarak di tunjukan pada pada gambar 1.1

Rele jarak pada umumnya telah dilengkapi elemen directional untuk menentukan arah atau letak gangguan sehingga membuat rele menjadi lebih selektif. Gambar dibawah ini menjelaskan secara sederhana prinsip kerja rele jarak elektro-mekanis yang didisain agar torsi operasi (operating torque) sebanding dengan arus yang terukur dan torsi penyeimbang (restraint torque) sebanding dengan tegangan yang terukur. Ketika terjadi gangguan akan timbul arus yang besar relatif terhadap tegangannya sehingga rasio V/I (impedansi) menjadi lebih kecil dan torsi operasi yang dihasilkan akan lebih besar daripada torsi penyeimbang. Kondisi ini akan menyebabkan kontak rele tertutup (trip).

Karakteristik mho ketika digambar dalam diagram impedansi R-X merupakan lingkaran dimana diameter lingkaran tersebut memotong titik pusat dari sistem koordinat dan besarnya diameter tersebut menggambarkan setelan jangkauan dan sudut fasa dari karakteristik mho. Setelan jangkauan dan sudut fasa karakteristik mho dapat di atur sama dengan impedansi saluran transmisi yang diproteksinya. Rele jarak dengan karakteristik mho akan bekerja apabila impedansi yang terukur berada didalam lingkaran. Rele jarak karakteristik mho seperti gambar 2.2

\section{Setting Rele Arus Lebih Waktu Terbalik (Invers Time)}

Rele arus lebih waktu terbalik memiliki batas setting yaitu rele tidak boleh bekerja saat beban maksimum, sehingga setting arus dari rele ini harus lebih besar dari arus beban penuh dari peralatan yang akan diamankan.

Pada rele arus lebih waktu terbalik terdiri dari dua bagian setting yaitu setting pickup dan setting time dial. Pada pickup besarnya arus pickup ditentukan dengan pemilihan tap. Untuk mengetahui setting rele arus lebih digunakan persamaan 2 berikut :

$1.05 \mathrm{I}_{\mathrm{FLA}}<\mathrm{I}_{\text {set }}<1.4 \mathrm{I}_{\mathrm{FLA}}$
Setting time dial digunakan untuk menentukan waktu operasi rele. Untuk menentukan nilai time dial dari masingmasing kurva karakteristik invers rele arus lebih dapat digunakan persamaan 3 dibawah.

$t d=\frac{k x T}{\beta x\left[\left(\frac{x}{b s t}\right)^{x}-1\right]}$

Dimana :

$\mathrm{td}=$ waktu operasi (detik)

$\mathrm{T}=$ time dial

$\mathrm{I}=$ nilai arus (Ampere)

Iset $=$ arus pickup (Ampere)

$\mathrm{k}=$ koefisien invers 1 (lihat pada tabel 1.1)

$\alpha=$ koefisien invers 2 (lihat pada tabel 1.1)

$\beta=$ koefisien invers 3 (lihat pada tabel 1.1)

\section{Setting Rele Arus Lebih Seketika (Instantaneous)}

Rele arus lebih seketika ini akan bekerja seketika jika ada arus lebih yang mengalir melebihi batas yang diijinkan. Untuk menentukan setting pickup dari rele arus lebih seketika dengan menggunakan nilai ISC min atau nilai arus hubung singkat antar fasa ([Ihs)_2 $\varphi$ ) pada pembangkitan minimum. Persamaan dibawah memperlihatkan setting dari rele arus lebih seketika :

Iset $\leq \mathrm{I}_{\mathrm{SC}} \min$

Dalam melakukan setting rele arus lebih seketika terdapat pertimbangan khusus pada pengaman feeder yang dipisahkan oleh sebuah transformator yang diperlihatkan pada gambar 3 . Persamaan yang digunakan dalam menentukan setting pickup adalah sebagai berikut :

$$
\mathrm{I}_{\mathrm{SC} \max \text { bus } 2} \leq \mathrm{Iset} \leq 0.8 \times \mathrm{I}_{\mathrm{SC} \text { min bus } 1}
$$

Dimana nilai Isc max bus 2 merupakan nilai arus hubung singkat tiga fasa maksimum ([Ihs $\rrbracket \_3 \varphi$ ) pada titik 2, sedangkan ISC min bus 1 merupakan arus hubung singkat minimum pada titik 1. Jika persamaan 5 terpenuhi maka setting time delay pada rele diatas transformator boleh kembali pada time delay 0.1 .

\section{SISTEM TRANSMISI 150 KV GI MLIWANG-TUBAN}

\section{A. Data dan Single Line Interkoneksi Transmisi GI}

1) Mliwang - Tuban

Di bawah ini adalah single line dari interkoneksi transmisi yang ada di GI Mliwang-Tuban, seperti di tunjukan pada gambar 3.1

Data sistem transmisi yang di butuhkan untuk perhitungan rele jarak seperti di tunjukan pada table 3.1

\section{B. Perancangan Perhitungan}

1) Perancangan perhitungan rele jarak

Algoritma yang digunakan dalam menganalisis unjuk kerja relay jarak adalah:

a. Membaca data masukan dari model sistem, yaitu impedansi saluran per kilometer, impedansi sumber, panjang saluran lokasi gangguan, jenis gangguan dan besarnya tahanan gangguan.. 
b. Menghitung setting rele jarak.

c. Menghitung besarnya tegangan dan arus gangguan yang dideteksi oleh rele, sesuai dengan jenis gangguan yang terjadi.

d. Menghitung besarnya impedansi gangguan yang dilihat tiap relay.

e. Mengevaluasi koordinasi rele jarak.

2) Perancangan perhitungan $O C R$

Algoritma yang digunakan dalam menganalisis unjuk kerja relay OCR adalah:

a. Membaca data masukan dari model sistem, yaitu impedansi saluran per kilometer, impedansi sumber, panjang saluran lokasi gangguan, jenis gangguan dan besarnya tahanan gangguan .

b. Menghitung setting OCR.

c. Menghitung besarnya arus gangguan yang dideteksi oleh relay, sesuai dengan jenis gangguan yang terjadi.

d. Menghitung waktu operasi OCR.

\section{SIMULASI DAN ANALISA}

\section{A. Perhitungan Setelan Rele Jarak Mliwang - Tuban}

Setelah di lakukan perhitungan maka di dapatkan hasil setting rele jarak saluran Tuban arah Mliwang seperti pada table 4.1, 4.2, 4.3

Hasil perhitungan rele jarak Mliwang arah Tuban seperti pada table 4.4 dan 4.5

\section{B. Setting OCR}

Karakteristik OCR adalah standart inverse. Perhitungan menggunakan CCC (CTprimer > CCC).

Rele arus lebih Tuban

OC1 (Reverse)

$\mathrm{T}_{\text {ocr }}=0,4$ detik

$\mathrm{I}_{\mathrm{set}}=1.2 * \mathrm{CCC}=1.2 * 973=1168 \mathrm{~A}$

$\operatorname{td}=\frac{k \times 1}{\beta \times\left[\left(\frac{1}{15 e t}\right)^{\alpha}-1\right]}, \quad$ TDS $=\left[\left(\frac{2150}{1168}\right)^{0,02}-1\right] \frac{0,4}{0,14}$

TDS $=0,035$

OC2 (Foward)

$\mathrm{T}_{\text {ocr }}=0,6$ detik

$\mathrm{I}_{\text {set }}=1.2 * \mathrm{CCC}=1.2 * 973=1168 \mathrm{~A}$

$\operatorname{td}=\frac{k \times 1}{\beta \times\left[\left(\frac{I}{I s e s}\right)^{\alpha}-1\right]}, \quad$ TDS $=\left[\left(\frac{3410}{1168}\right)^{0,02}-1\right] \frac{0,6}{0,14}$

TDS $=0,093$

Rele arus lebih Mliwang

OC1 (Forward)

$\mathrm{T}_{\text {ocr }}=0,4$ detik

$\mathrm{I}_{\mathrm{set}}=1.2 * \mathrm{CCC}=1.2 * 973=1168 \mathrm{~A}$ $\operatorname{td}=\frac{k \times T}{\beta \times\left[\left(\frac{1}{\operatorname{Iset}}\right)^{\alpha}-1\right]}, \quad$ TDS $=\left[\left(\frac{3430}{1168}\right)^{0,02}-1\right] \frac{0,4}{0,14}$

$\operatorname{TDS}=0,062$

OC2 (Reverse)

$\mathrm{T}_{\text {ocr }}=0,6$ detik

$\mathrm{I}_{\text {set }}=1.2 * \mathrm{CCC}=1.2 * 973=1168 \mathrm{~A}$

$\operatorname{td}=\frac{k \times 1}{\beta \times\left[\left(\frac{I}{I s 8 t}\right)^{\alpha}-1\right]}, \quad \operatorname{TDS}=\left[\left(\frac{1880}{1168}\right)^{0,02}-1\right] \frac{0,6}{0,14}$

TDS $=0,04$

\section{Koordinasi Rele Jarak dan OCR}

Untuk mendapatkan setting yang tepat, maka koordinasi waktu antara rele jarak sebagai proteksi utama dan rele arus lebih sebagai proteksi cadangan lokal pada saluran transmisi harus di atur. Waktu trip antar rele harus memenuhi kaidah proteksi transmisi.

Koordinasi waktu GI Tuban.

Waktu kerja rele arus lebih untuk selanjutnya akan di koordinasikan dengan waktu kerja rele jarak.

Waktu kerja rele arus lebih untuk selanjutnya akan di koordinasikan dengan waktu kerja rele jarak.

Dari gambar di atas dapat di simpulkan bahwa semakin mendekati Bus yang di proteksi, maka arus gangguan semakin besar sehingga rele arus lebih bekerja dengan waktu lebih cepat.

Rele jarak sebagai pengaman utama saluran transmisi akan bekerja lebih dulu saat berfungsi sebagai proteksi cadangan jauh pada gangguan di $100 \%$ zona proteksi dalam $0,4 \mathrm{~s}$, maka karena itu rele arus lebih sebagai back-up di setting waktunya 0,6 s sehingga tidak overlapping dengan rele jarak.. Pada gangguan zona 1 proteksi rele jarak, maka rele jarak akan bekerja instan dan rele arus lebih sebagai back-up akan bekerja lebih lambat 0,3 detik.

Maka koordinasi waktu rele jarak dan rele arus lebih sudah sesuai kaidah proteksi transmisi

\section{Faktor Kompensasi Urutan Nol (KO)}

Pada gangguan satu fasa atau dua fasa ke tanah, pengukuran impedansi akan mencakup pula impedansi urutan nol. Hal ini dapat menyebabkan terjadinya kesalahan pengukuran (underreach) untuk gangguan satu fasa maupun 


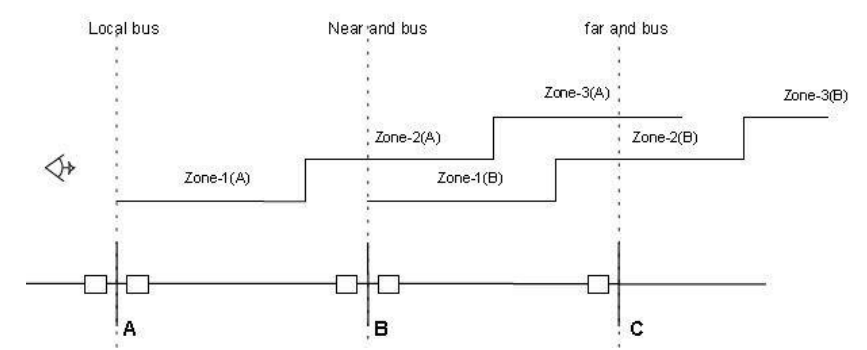

Gambar 2.1 Skema rele jarak

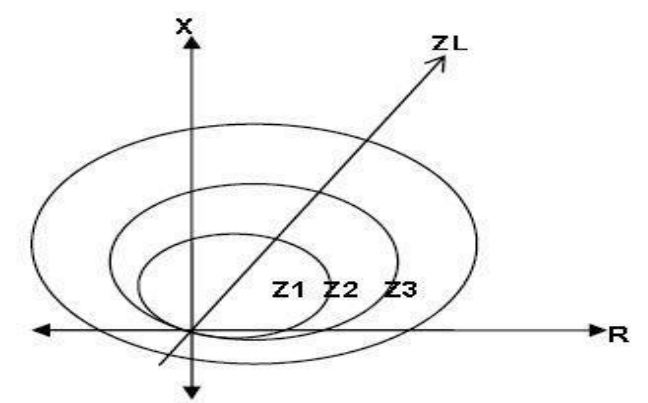

Gambar 2. 2 Karakteristik Mho

Setting rele jarak

Zona I

Zone $1=0.8 \times \mathrm{Z} 12$

Zona II

Zone $2 \min =1.2 \times \mathrm{Z} 12$

Zone 2 max $=\mathrm{Z} 12+50 \% \mathrm{x}$ k.Z23

(Z23 saluran terpendek)

Zona III

Zone $3 \mathrm{~min}=\mathrm{Z} 12+1.2 \mathrm{Z} 23$

Zone $3 \max =1.2(\mathrm{Z} 12+\mathrm{k} . \mathrm{Z} 23)$

(Z23 saluran terpanjang)

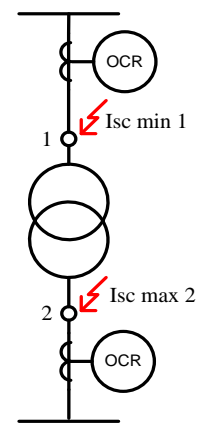

Gambar 2.3 Rele arus lebih pengaman transformator

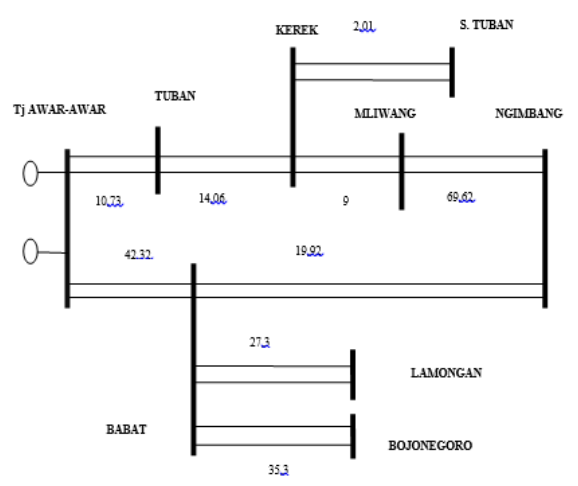

Gambar 3.1 Single line diagram interkoneksi transmisi

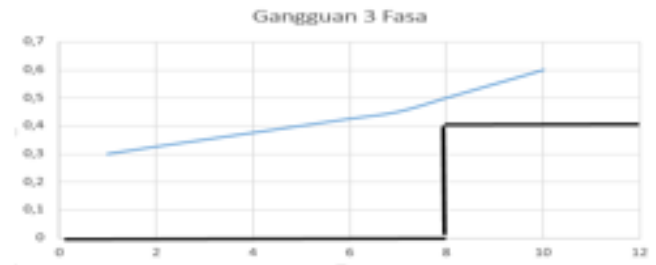

Gambar 4.1 Koordinasi waktu 3 fasa

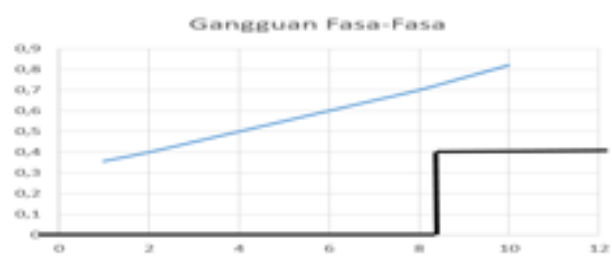

Gambar 4.2 Koordinasi waktu 3 fasa

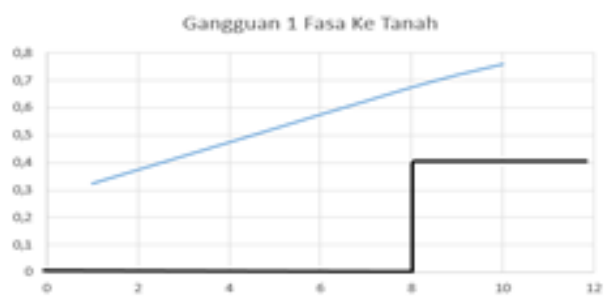

Gambar 4.3 Koordinasi waktu 1 fasa-tanah

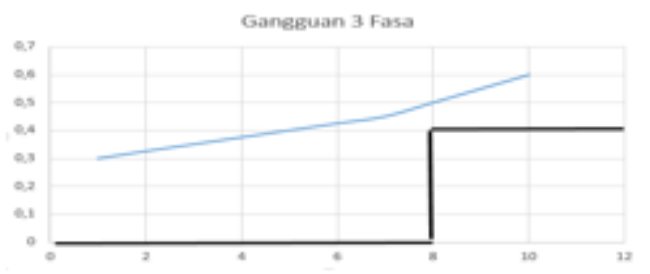

Gambar 4.4 Koordinasi waktu 3 fasa

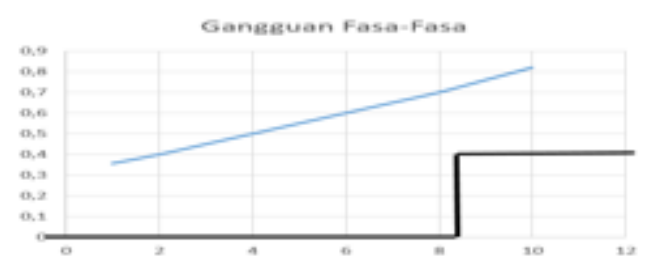

Gambar 4.5 Koordinasi waktu 3 fasa

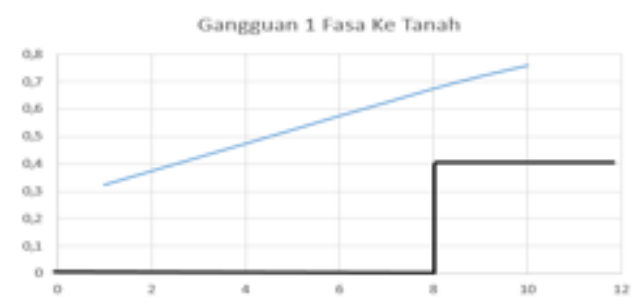

Gambar 4.6 Koordinasi waktu 1 fasa-tanah

Tabel 2.1 Koefisien invers time dial

\begin{tabular}{llll}
\hline \hline Tipe Kurva & Koefisien & & \\
& $\boldsymbol{k}$ & $\boldsymbol{\alpha}$ & $\boldsymbol{\beta}$ \\
\hline Standard Inverse & 0.14 & 0.02 & 2.970 \\
Very Invers & 13.50 & 1.00 & 1.500 \\
Extremely Inverse & 80.0 & 2.00 & 0.808 \\
\hline \hline
\end{tabular}


Tabel 3.1 Data system transmisi

\begin{tabular}{|c|c|c|c|c|}
\hline $\begin{array}{l}\text { SUTT } 150 \\
\mathrm{kV}\end{array}$ & $\begin{array}{l}\text { Tipe } \\
\text { Konduktor }\end{array}$ & $\begin{array}{l}\text { CCC } \\
\text { (A) }\end{array}$ & $\begin{array}{l}\text { Panjang } \\
\text { Saluran } \\
(\mathbf{k m})\end{array}$ & $\begin{array}{l}\text { Impedansi } \\
\text { Saluran }(Z) \text { per } \\
\text { km }\end{array}$ \\
\hline $\begin{array}{l}\text { Tj Awar- } \\
\text { Tuban }\end{array}$ & $\begin{array}{l}\text { TACSR } 2 X \\
410 / 67 \mathrm{~mm}^{2}\end{array}$ & 2730 & 10,7393 & $0.038+\mathrm{j} 0.279$ \\
\hline $\begin{array}{l}\text { Tuban- } \\
\text { Kerek }\end{array}$ & $\begin{array}{l}\text { TACSR } 240 \\
\mathrm{~mm}^{2}\end{array}$ & 973 & 14,06 & $\begin{array}{l}0.12669 \\
+\mathrm{j} 0.3877\end{array}$ \\
\hline $\begin{array}{l}\text { Kerek- } \\
\text { Mliwang }\end{array}$ & $\begin{array}{l}\text { TACSR } 240 \\
\mathrm{~mm}^{2}\end{array}$ & 973 & 9 & $\begin{array}{l}0.12669 \\
+\mathrm{j} 0.3877\end{array}$ \\
\hline $\begin{array}{l}\text { Kerek - } \\
\text { Semen }\end{array}$ & $\begin{array}{l}\text { TACSR } 240 \\
\mathrm{~mm}^{2}\end{array}$ & 973 & 2,012 & $\begin{array}{l}0.12669 \\
+\mathrm{j} 0.3877\end{array}$ \\
\hline $\begin{array}{l}\text { Mliwang- } \\
\text { Ngimbang }\end{array}$ & $\begin{array}{l}\text { ZEBRA } 2 \text { X } \\
484.5 \mathrm{~mm}^{2}\end{array}$ & 1620 & 69,62 & $\begin{array}{l}0,0387 \\
+\mathrm{j} 0.28070\end{array}$ \\
\hline
\end{tabular}

Tabel 4.2 Setting sekunder Tuban arah Kerek 1

\begin{tabular}{llllll}
\hline \hline & $\begin{array}{l}\text { Setting } \\
|\Omega|\end{array}$ & & $\begin{array}{l}\text { Setting } \\
\Omega\end{array}$ & $\begin{array}{l}\text { Waktu } \\
\text { (detik) }\end{array}$ \\
\hline Zona 1 & 4,58 & $<71,90^{\circ}$ & 1,4250 & $\mathrm{j} 4,3608$ & 0 \\
Zona 2 & 6,88 & $<71,90^{\circ}$ & 2,1375 & $\mathrm{j} 6,5412$ & 0,4 \\
Zona 3 & 15,69 & $<71,90^{\circ}$ & 4,874 & $\mathrm{j} 14,915$ & 1,2 \\
\hline \hline
\end{tabular}

Tabel 4.3 Setting sekunder Tuban arah Kerek 2

\begin{tabular}{llllll}
\hline \hline & Setting & & Setting & & $\begin{array}{l}\text { Waktu } \\
\text { (detik) }\end{array}$ \\
\hline Zona 1 & 0,524 & $<72,09^{\circ}$ & 0,1628 & $\mathrm{j} 049838$ & 0 \\
Zona 2 & 0,78 & $<71,90^{\circ}$ & 0,2442 & $\mathrm{j} 0,7475$ & 0,4 \\
Zona 3 & 1,79 & $<71,90^{\circ}$ & 0,557 & $\mathrm{j} 1,704$ & 1,2 \\
\hline \hline
\end{tabular}

Tabel 4.4 Setting primer Mliwang arah Kerek 1 dan 2

\begin{tabular}{llllll}
\hline \hline Jarak(\%) & 0,2 & 0,4 & 0,6 & 0,8 & 1 \\
\hline Waktu(s) & 0,3 & 03 & 0,42 & 0,5 & 0,6 \\
\hline \hline
\end{tabular}

Tabel 4.5 Setting sekunder Mliwang arah Kerek 1dan 2

\begin{tabular}{llllll}
\hline \hline & $\begin{array}{l}\text { Setting } \\
|\Omega|\end{array}$ & & $\begin{array}{l}\text { Setting } \\
\Omega\end{array}$ & $\begin{array}{l}\text { Waktu } \\
\text { (detik) }\end{array}$ \\
\hline Zona 1 & 0,66 & $<72,09^{\circ}$ & 0,2035 & $\mathrm{j} 0,6229$ & 0 \\
Zona 2 & 0,98 & $<71,90^{\circ}$ & 0,3053 & $\mathrm{j} 0,9344$ & 0,4 \\
Zona 3 & 2,24 & $<71,90^{\circ}$ & 0,696 & $\mathrm{j} 2,13$ & 1,2 \\
\hline \hline
\end{tabular}

Tabel 4.6 Setting OCR

\begin{tabular}{llllll}
\hline \hline & $\begin{array}{l}\text { Setting } \\
|\Omega|\end{array}$ & & $\begin{array}{l}\text { Setting } \\
\Omega\end{array}$ & $\begin{array}{l}\text { Waktu } \\
\text { (detik) }\end{array}$ \\
\hline Zona 1 & 2,93 & $<71,90^{\circ}$ & 0,91217 & $\mathrm{j} 2,7914$ & 0 \\
Zona 2 & 4,49 & $<71,84^{\circ}$ & 1,40 & $\mathrm{j} 4,27$ & 0,4 \\
Zona 3 & 18,167 & $<71,89^{\circ}$ & 5,643 & $\mathrm{j} 12,269$ & 1,2 \\
\hline \hline
\end{tabular}

\begin{tabular}{llllll}
\hline \hline & Setting & & Setting & & $\begin{array}{l}\text { Waktu } \\
\text { (detik) }\end{array}$ \\
\hline Zona 1 & 0,33 & $<71,90^{\circ}$ & 0,10425 & $\mathrm{j} 0,31902$ & 0 \\
Zona 2 & 0,51 & $<71,91^{\circ}$ & 0,16 & $\mathrm{j} 0,49$ & 0,4 \\
Zona 3 & 2,075 & $<71,89^{\circ}$ & 0,64495 & $\mathrm{j} 1,973$ & 1,2 \\
\hline \hline
\end{tabular}

Tabel 4.7 Waktu trip OCR gangguan 3 fasa

\begin{tabular}{lllll}
\hline \hline Lokasi & Iset & Iset & TDS & TDS \\
& OC1 & OC2 & OC1 & OC2 \\
\hline Tuban & 1168 & 1168 & 0,035 & 0,093 \\
Mliwang & 1168 & 1168 & 0,062 & 0,04 \\
\hline \hline
\end{tabular}

Tabel 4.8 Waktu trip OCR gangguan fasa-fasa

\begin{tabular}{llllll}
\hline \hline Jarak(\%) & 0,2 & 0,4 & 0,6 & 0,8 & 1 \\
\hline Waktu(s) & 0,4 & 0,55 & 0,65 & 0,7 & 0,81 \\
\hline \hline & & & \\
& Tabel 4.9 Waktu trip OCR gangguan 1 fasa-tanah \\
\hline \hline Jarak(\%) & 0,2 & 0,4 & 0,6 & 0,8 & 1 \\
\hline Waktu(s) & 0,7 & 0,52 & 0,61 & 0,7 & 0,75 \\
\hline \hline
\end{tabular}

Tabel 4.10 Waktu trip OCR gangguan 3 fasa

\begin{tabular}{llllll}
\hline \hline Jarak(\%) & 0,2 & 0,4 & 0,6 & 0,8 & 1 \\
\hline Waktu(s) & 0,345 & 0,39 & 0,45 & 0,55 & 0,62 \\
\hline \hline
\end{tabular}

Tabel 4.11 Waktu trip OCR gangguan fasa-fasa

\begin{tabular}{llllll}
\hline \hline Jarak(\%) & 0,2 & 0,4 & 0,6 & 0,8 & 1 \\
\hline Waktu(s) & 0,39 & 0,56 & 0,67 & 0,75 & 0,82 \\
\hline \hline \multicolumn{7}{c}{ Tabel 4.12 Waktu trip OCR gangguan 1 fasa-tanah } \\
\hline \hline Jarak(\%) & 0,2 & 0,4 & 0,6 & 0,8 & 1 \\
\hline Waktu(s) & 0,383 & 0,56 & 0,63 & 0,7 & 0,75 \\
\hline \hline
\end{tabular}

dua fasa ke tanah.

Untuk gangguan fasa ke tanah, dengan menambahkan faktor kompensasi urutan nol pada pengukuran arus maka impedansi yang diukur adalah impedansi urutan positif penghantar.

$$
\begin{aligned}
& \mathrm{K}_{0}=\left(\frac{z 0-Z 1}{3 Z 1}\right) \\
& \mathrm{K}_{0}=0,3050<-8,1^{0}
\end{aligned}
$$

Keterangan :

$\mathrm{K}_{0}$ = faktor kompensasi gangguan ke tanah

\section{E. Batasan Jangkauan Resistif Terhadap Beban}

Rele jarak juga harus dapat membedakan antara impedansi pada saat kondisi berbeban dengan impedansi pada saat terjadi gangguan, sehingga setelan jangkauan rele jarak harus dibatasi tidak boleh menjangkau daerah impedansi beban (load area).

1. Relay Tuban arah kerek 1

$$
\begin{aligned}
\mathrm{Zload} & =0.5 \frac{V L L}{\sqrt{3} I} \mathrm{n} \\
& =0.5 \frac{150 \mathrm{Kv}}{\sqrt{3} 973} 0,114 \\
& =5 \mathrm{Ohm}<36,86^{0}
\end{aligned}
$$

2. Relay Tuban arah kerek 2

$$
\begin{aligned}
\mathrm{Zload} & =0.5 \frac{V L L}{\sqrt{3} I} \mathrm{n} \\
& =0.5 \frac{150 \mathrm{Kv}}{\sqrt{3} 973} 0,142 \\
& =6,319 \mathrm{Ohm}<36,86^{0}
\end{aligned}
$$

3. Relay Mliwang arah kerek $1 \& 2$

$$
\mathrm{Z} \text { load }=0.5 \frac{V L L}{\sqrt{3} I} \mathrm{n}
$$




$$
\begin{aligned}
& =0.5 \frac{150 \mathrm{Kv}}{\sqrt{3} 973} 0,114 \\
& =5 \mathrm{Ohm}<36,86^{0}
\end{aligned}
$$

\section{F. Skema Teleproteksi}

Ada dua faktor utama yang menjadi pertimbangan digunakannya peralatan teleproteksi pada rele jarak yaitu :

Gangguan yang tidak diamankan secara langsung (time delay) seperti pada zona dua rele jarak, dapat menyebabkan sistem menjadi tidak stabil.

Jika pada saluran transmisi yang diamankan menggunakan peralatan auto reclose, perbedaan waktu trip di kedua ujung saluran tranmisi dapat mengganggu kinerja auto reclose.

Pola teleproteksi rele yang dipilih adalah pola PUTT (Permissive Underreach Transfer Trip), pemilihan pola ini dikarenakan pertimbangan faktor keamanan yaitu jika terjadi kegagalan atau gangguan pengiriman sinyal, gangguan yang terjadi tetap dapat diamankan menggunakan skema rele jarak konvensional (step distance). Prinsip kerja pola PUTT adalah :

1. Zone 1 operation $\rightarrow$ Instantaneous trip + signal transmit

2. Zone 2 operation + signal receive $\rightarrow$ Instantaneous trip

\section{PENUTUP}

\section{A. Kesimpulan}

Dari analisa dan pembahasan pada Tugas Akhir ini, dapat ditarik beberapa kesimpulan sebagai berikut:

1. Setting impedansi zona 1 dan zona 2 rele jarak baik dari data di di PLN ( Persero) APP Madiun dengan analisa perhitungan yang di lakukan perbedaanya tidak terlalu jauh. Sehingga setting yang terpasang masih bisa di pakai

2. Setting impedansi zona 3 antara hasil analisa dan dari data setting dari PLN (Persero ) APP Madiun terdapat perbedaan sehingga perlu peninjauan setting kembali untuk mendapatkan setting rele jarak yang tepat.

3. Besarnya infeed rele sebanding dengan jarak lokasi gangguan dari rele dan berpengaruh pada unjuk kerja rele jarak karena infeed rele menentukan besarnya tahanan gangguan yang dilihat oleh rele jarak .

4. Semakin kecil nilai arus hubung singkat maka waktu operasi rele arus lebih (OCR) semakin besar.

5. Koordinasi waktu antara relay jarak sebagai pengaman utama dan OCR sebagai pengaman cadangan lokal sudah tepat karena grafik waktu operasi masing-masing rele tidak saling berpotongan

\section{B. Saran}

Untuk keperluan pengembangan Tugas Akhir ini, maka dapat diberikan saran-saran sebagai berikut:

1. Dilakukan pembahasan unjuk kerja rele jarak untuk karakteristik yang lain untuk mengetahui pemilihan karakteristik rele jarak yang tepat untuk mengatasi tipe gangguan hubung singkat yang terjadi.

2. Menambah pembahasan koordinasi waktu rele jarak sebagai pengaman cadangan jauh (remote backup protection) dari saluran lain.

\section{DAFTAR PUSTAKA}

[1] Christopoulos, C, Wright, A. "Electrical Power System Protection", Chapman \& Hall : London : 1993

[2] Das J.C. "Power System Anayisis Short-Circuit Load Flow And Harmonic " Marcel Dekker Inc. Newyork : 2002

[3] Gonen, Turan. "Modern Power System Analysis". John Wiley \& Son, Inc. 1988

[4] Alstom. "Network Protection \& Automation Guide". Alstom Grid : 2011

[5] Wahyudi, Ir. "Buku Pegangan Kuliah Proteksi Sistem Tenaga " Elektro ITS: 2016

[6] Paithankar, Y.G. Bhide, S.R."Fundamental Of Power System Protection", Prentice-Hall of INDIA. New Delhi.2003.

[7] Saadat, Hadi. 1999. " Power System Analysis ". New York : The McGraw-Hill Companies.

[8] Lazar irwin "Electrical System Analysis and Design for Industrial Plant”, McGraw-Hill Inc., USA, Ch, 1, 1980

[9] Stevenson, Jr, William, D. "Analisa sistem tenaga listrik " edisi keempat, Erlangga: Jakarta : 1994

[10] Zuhal, "Dasar Teknik Tenaga Listrik dan Elekronika Daya", PT Gramedia Pustaka Utama, Jakarta:1992

[11] PT. PLN (Persero) P3B. "Pelatihan O\&M Relai Proteksi Jaringan" September 2005.

[12] PT. PLN (Persero) P3B “Diklat Kursus Rele Proteksi” Semarang : 2007 